\title{
Facile Preparation of Phosphotungstic Acid-Impregnated Yeast Hybrid Microspheres and Their Photocatalytic Performance for Decolorization of Azo Dye
}

\author{
Lan Chen and Bo Bai \\ College of Environmental Science and Engineering, Chang'an University, Xi'an 710054, China \\ Correspondence should be addressed to Bo Bai; baibo@chd.edu.cn
}

Received 16 January 2013; Revised 9 April 2013; Accepted 9 April 2013

Academic Editor: Elias Stathatos

Copyright (C) 2013 L. Chen and B. Bai. This is an open access article distributed under the Creative Commons Attribution License, which permits unrestricted use, distribution, and reproduction in any medium, provided the original work is properly cited.

\begin{abstract}
Phosphotungstic acid (HPW)-impregnated yeast hybrid microspheres were prepared by impregnation-adsorption technique through tuning $\mathrm{pH}$ of the aqueous yeast suspensions. The obtained products were characterized by field emission scanning electron microscopy (FE-SEM), energy dispersive spectrometry (EDS), X-ray diffraction (XRD), thermogravimetry-differential scanning calorimetry (TG-DSC), and ultraviolet-visible spectrophotometry (UV-Vis), respectively. FE-SEM and EDS ascertain that the HPW has been effectively introduced onto the surface of yeast, and the resulting samples retain ellipsoid shape, with the uniform size (length $4.5 \pm 0.2 \mu \mathrm{m}$, width $3.0 \pm 0.3 \mu \mathrm{m}$ ) and good monodispersion. XRD pattern indicates that the main crystal structure of assynthesized HPW@yeast microsphere is Keggin structure. TG-DTA states that the HPW in composites has better thermal stability than pure HPW. Fourier transform infrared spectroscopy (FT-IR) elucidates that the functional groups or chemical bonds inherited from the pristine yeast cell were critical to the assembling of the composites. UV-Vis shows that the obtained samples have a good responding to UV light. The settling ability indicates that the hybrid microspheres possess an excellent suspension performance. In the test of catalytic activity, the HPW@yeast microsphere exhibits a high photocatalytic activity for the decoloration of Methylene blue and Congo red dye aqueous solutions, and there are a few activity losses after four cycles of uses.
\end{abstract}

\section{Introduction}

Solid heteropoly acids (HPAs), a kind of environmentalfriendly catalysts, could replace liquid acids to minimize the pollution damage to the environment [1-3]. Among various HPAs structural classes, Keggin-type HPAs, especially Keggin phosphotungstic acid $\left(\mathrm{H}_{3} \mathrm{PW}_{12} \mathrm{O}_{40}, \mathrm{HPW}\right)$, have strong acidity and high conductivity [4]. By this means, a few of previous research studies have focused on the application of HPW for the photodecomposition of various kinds of environmental problems through fully making use of its strong Brønsted acidity character, redox properties, and the quasiliquid properties [5-9]. Till now, utilizing homogeneous HPA as photocatalysts in the polluted aqueous solution is very common $[10,11]$. However, from a practical point of view, it may not be possible to employ this HPW as homogeneous reaction in photoreactor because of its easy solubility in polar solvent, which inevitably leads to an expensive and time-consuming separation and recovery of photocatalysts from solvent [12]. In addition, the low specific surface area or low thermostability of HPA particles makes it difficult to improve its catalytic activity effectively [13]. To solve these problems, a few alternative strategies have been proposed to support HPW catalysts on the surface of adsorbent substance. For instance, Gao et al. [14] obtained carbonized resin-12-phosphotungstic acid (HPW) catalyst by employing carbonized resin as support. Wen et al. [15] fabricated $\mathrm{HPW} / \mathrm{SiO}_{2}$ successfully by using a series of $\mathrm{SiO}_{2}$ as supports and further demonstrated that the catalytic performance of $\mathrm{HPW} / \mathrm{SiO}_{2}$ in alkylation reactions remarkably depended on the properties of the silica support. Obalı and Dogu [16] described the fabrication of activated carbon-tungstophosphoric acid catalysts via utilization of activated carbon as supports and the composites catalysts have a better catalytic activity than pure HPW for the synthesis of tert-amyl ethyl ether (TAEE). Yang et al. [17] prepared $\mathrm{H}_{3} \mathrm{PW}_{12} \mathrm{O}_{40} / \mathrm{MCM}-48$ composite photocatalyst by 
loading phosphotungstic acid on the mesoporous MCM- 48 and the test of catalytic activity shows that the degradation of methyl orange aqueous solution could reach $84.53 \%$.

Recently, yeasts as biotemplates or supports to synthesize catalysts have attracted considerable attention. For example, $\mathrm{He}$ et al. [18] synthesized $\mathrm{Cu}_{2} \mathrm{O}$ hollow spheres by employing yeasts as biotemplates. Weinziel et al. [19] prepared $\mathrm{SiO}_{2}$ hollow particles using yeasts as biotemplates. Our groups [20] obtained the raspberry-like $\mathrm{TiO}_{2} @ y e a s t$ composite photocatalysts successfully by exploiting yeasts as supports. To sum up, a serial of excellent merits have been brought along for the obtained composite catalysts [21]. Typical benefits include the following. (1) The tunable and uniform shape of supports can be easily achieved from the abundant microbial cells resources in nature. (2) Additional surface modification can be left out due to the preexistence of functional groups inherited from the hydrophilic cell wall of microbial cells. (3) The composites using yeasts as supports have integrated properties originating from their hybrid components, which represent a new style of economical and environmentalfriendly catalysts [20].

Thus, in the present work, the phosphotungstic acid (HPW)-impregnated yeast (HPW@yeast) hybrid microspheres were prepared by impregnation-adsorption technique through tuning $\mathrm{pH}$ of the aqueous yeast suspensions firstly. Then the obtained hybrid microspheres were characterized by SEM, EDS, XRD, FT-IR, and UV-Vis, respectively. A possible mechanism for the formation of the composite microspheres was proposed. Moreover, the photocatalytic activities of HPW@yeasts microspheres were evaluated by examining the decolorization of Methylene blue and Congo red. The reusability of HPW@yeast as catalyst was estimated further.

\section{Experimental}

2.1. Materials. Yeast powder was purchased from Angel Yeast Co. Analytical grade phosphotungstic acid (HPW) sulphuric acid $\left(\mathrm{H}_{2} \mathrm{SO}_{4}\right)$ was provided by Xỉn Chemical Agent Corp. and used without further purification. Double distilled water and absolute ethanol were used throughout the experimental procedures.

2.2. Synthesis of HPW@yeast Hybrid Microsphere. In a typical synthesis procedure, $1.000 \mathrm{~g}$ yeast powder was washed with distilled water and ethanol for three times, respectively. The washed yeast was dispersed in $50 \mathrm{~mL}$ of distilled water. The $\mathrm{pH}$ was adjusted to approximately 2-3 by adding dropwise sulphuric acid. The suspension was magnetically stirred for $30 \mathrm{~min}$ to facilitate the dispersion of the yeast particles. $300 \mathrm{mg}$ HPW dissolved in $40 \mathrm{~mL}$ ethanol was added to the previously mentioned suspensions with constant stirring. The mixture was continuously magnetically stirred for $1.0 \mathrm{~h}$ at room temperature and then left for $3 \mathrm{~h}$ without further stirring or shaking to ensure the formation of HPW@yeast heterocoagulated particles. Then, the mixture was collected by centrifugation, followed by three cycles of distilled water and ethanol rinsing, to get filtrate precipitation, and finally dried in drying oven at $60 \sim 80^{\circ} \mathrm{C}$ for $40 \mathrm{~min}$. After that, the HPW@yeast composite microspheres were obtained.

2.3. Characterization of Samples. X-ray diffraction (XRD) patterns of the samples were carried out on a Regaku D/MAX-3C diffractometer operated at a voltage of $40 \mathrm{kV}$ and a current of $20 \mathrm{~mA}$ at a $0.02^{\circ}$ scan rate with $\mathrm{Cu} \mathrm{K \alpha}$ radiation. Field-emission scanning electromicroscope (FESEM) images were taken on a JEOL-6300F field-emission scanning electromicroscope with an accelerating voltage of $15 \mathrm{kV}$. Fourier-transform infrared (FT-IR) spectroscopy measurements were recorded with a Bruker TENSOR 27 FT-IR spectrometer. Thermal gravimetric analysis (TG) and differential scanning calorimetry (DSC) were performed on a HCT-2 apparatus at a heating rate of $10^{\circ} \mathrm{C} / \mathrm{min}$.

2.4. The Setting Performance.0.050 g HPW@yeast microspheres were dispersed into $50 \mathrm{~mL}$ of distilled water in a vertical cylindrical burette at room temperature. At regular intervals, the falling height was determined. The sedimentation ratio $(R)$ was measured by

$$
R=\frac{a}{a+b} \times 100 \%
$$

where $a$ is the length of the clear fluid and $b$ is the length of the turbid fluid, respectively.

2.5. Catalytic Activity. The photocatalytic activity of the prepared samples was evaluated by the photocatalytic decolorization of anion dye Congo Red and cationic dyes Methylene Blue $(\mathrm{MB})$ at room temperature. The experimental procedure was as follows: $100 \mathrm{mg}$ of the prepared powders was dispersed in $100 \mathrm{~mL}$ of $\mathrm{MB}$ aqueous solution with a concentration of $12 \mathrm{mg} / \mathrm{L}$ in a beaker (with a capacity of $150 \mathrm{~mL}$ ), and the suspensions were magnetically stirred in the dark for $30 \mathrm{~min}$, prior to irradiation with UV light. The UV-light lamp placed $7 \mathrm{~cm}$ above the beaker was used as a light source. The concentration of MB aqueous solution was determined by a UV-visible spectrophotometer (TU-4100). Before and after irradiation, samples $(6 \mathrm{~mL})$ were collected at regular intervals. Each sample was centrifuged to separate the catalyst from the liquid and the supernatant was analyzed. The samples were returned into the reactor immediately after each analysis.

In order to evaluate the reusability of the obtained microspheres in the photocatalytic processes, the measurement of the lifetime of the HPW@yeast was assessed. The experimental procedure was the same as the photocatalytic activity test aforementioned. The only difference is that the experiment was operated four times. In each experiment, the catalysts were centrifuged and recovered from the photocatalytic system without other treatments that would be as catalyst for the other photodegradation experiments. 


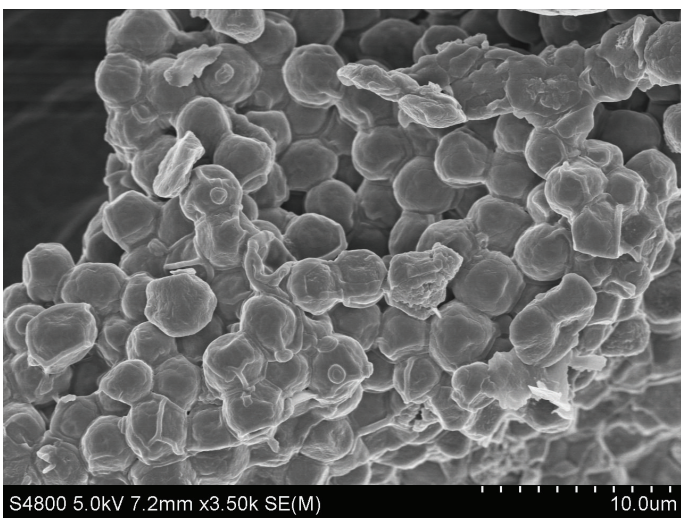

(a)

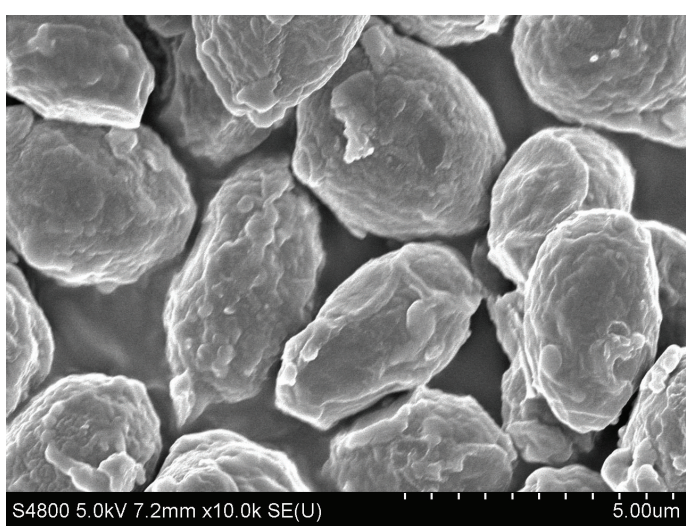

(c)

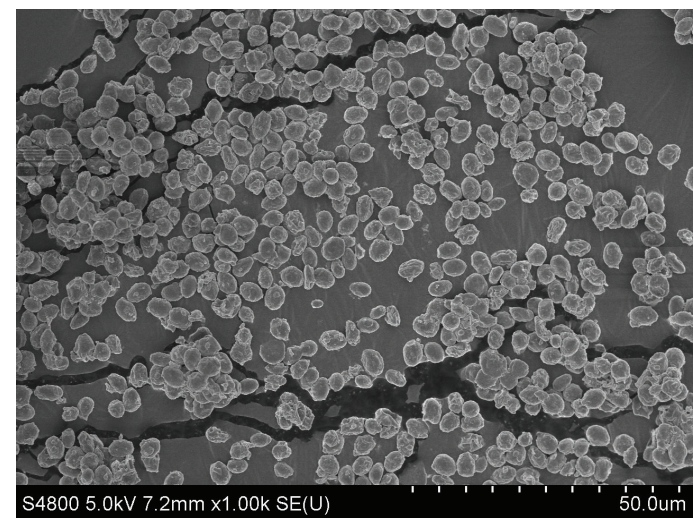

(b)

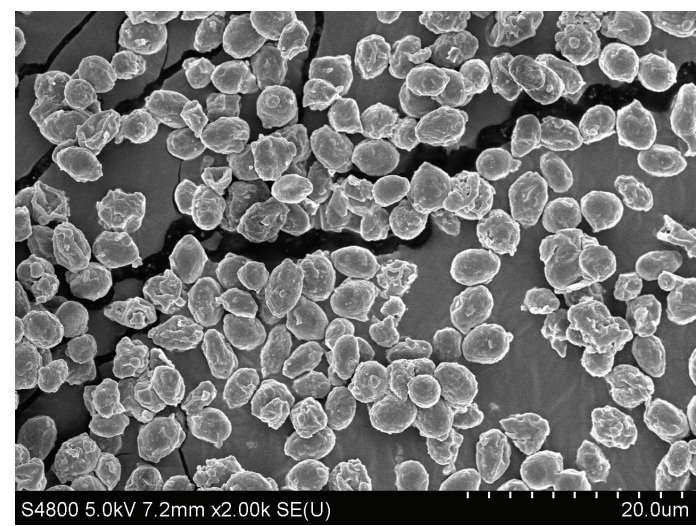

(d)

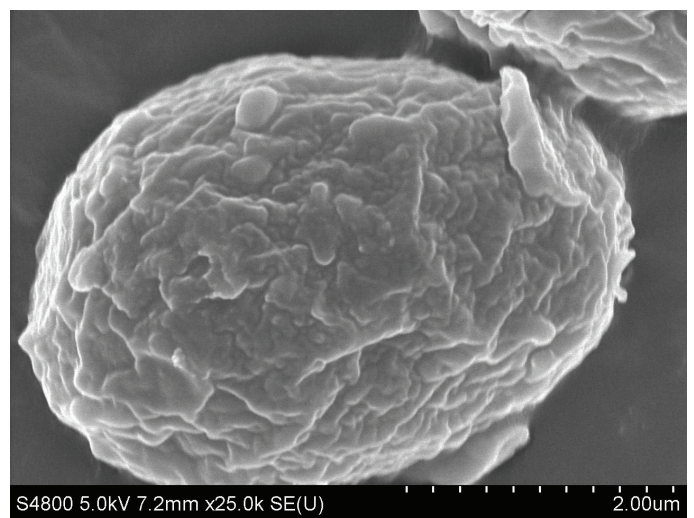

(e)

FIGURE 1: FE-SEM images of (a) yeast and (b, c, d, and e) HPW@yeast microspheres observed under different magnifications.

\section{Results and Discussion}

3.1. FE-SEM and EDS. The morphologies of yeast and HPW@yeast particles under the different magnifications are showed in Figure 1. Figure 1(a) displays that the morphology of the naked yeast washed with distilled water and ethanol is approximately spherical with the diameter ranging from $3.1 \mu \mathrm{m}$ to $4.1 \mu \mathrm{m}$. In Figures $1(\mathrm{~b})$ and $1(\mathrm{c})$, the HPW@yeast microspheres maintain shape of the primitive yeast with relatively good monodispersity. From the high-magnification images in Figure 1(d), it is clearly seen that each of microspheres has ordered elliptic shapes of uniform size with the length of $4.5 \pm 0.2 \mu \mathrm{m}$ and width of $3.0 \pm 0.2 \mu \mathrm{m}$. Compared with the naked yeast, the diameter of the HPW@yeast microspheres has increased only by a small amount, which arises from the attachment of HPW particles onto the surface of yeast core. The higher resolution picture of a single HPW@yeast microsphere (Figure 1(e)) indicates that the surface of species has smooth and continuous textural taints, although part of areas on the surface of the species still remains rough and unsmooth. 


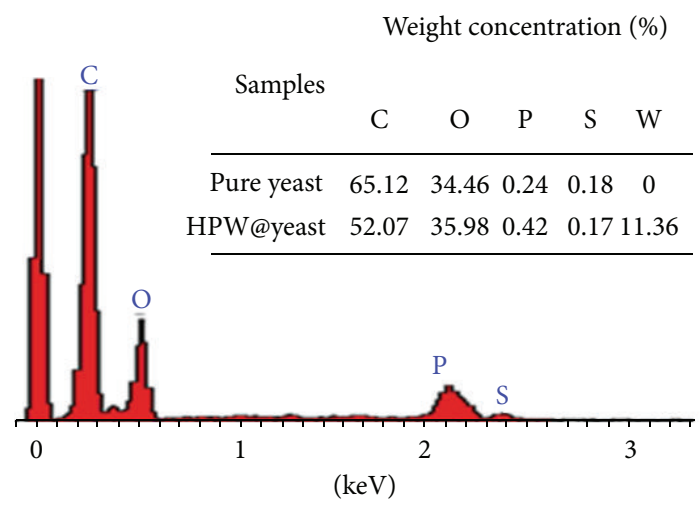

(a)

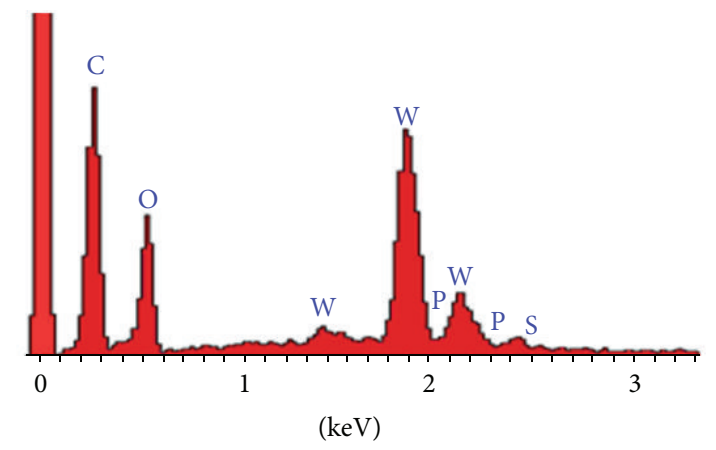

(b)

FIGURE 2: EDS spectra of (a) bare yeast and (b) HPW@yeast samples.

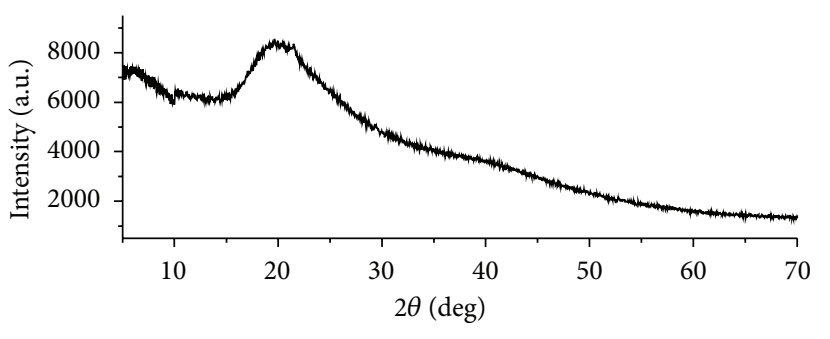

(a)

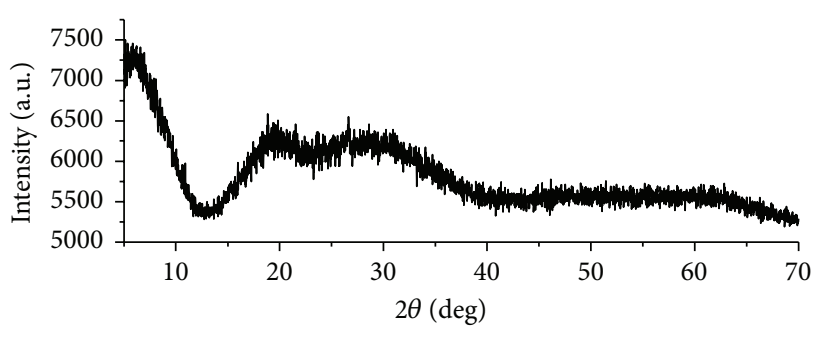

(b)

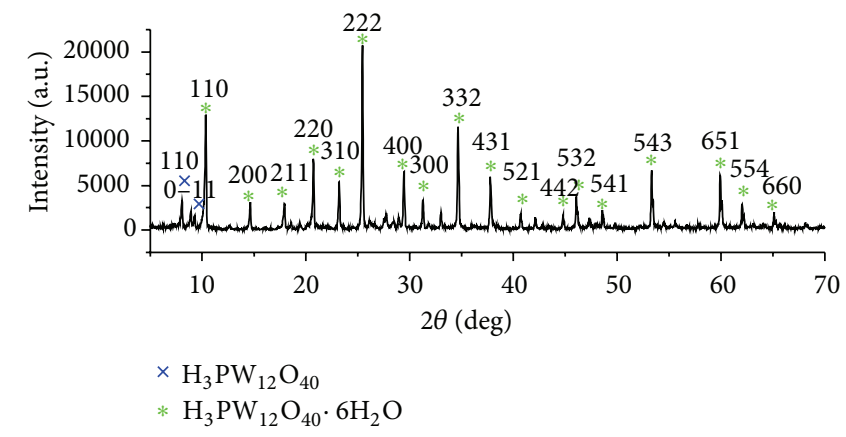

(c)

FIGURE 3: XRD patterns of (a) yeast, (b) HPW@yeast, and (c) HPW.

In order to ascertain the detailed structures of HPW@ yeast composites, EDS was used to characterize the change of elemental concentration on the yeast cores and final HPW@yeast composites, respectively. The results are shown in Figure 2. For the yeast core, the peaks corresponding to $\mathrm{C}, \mathrm{O}, \mathrm{P}$, and $\mathrm{S}$ are observed in Figure 2(a). After the coverage of HPW on the yeast surface, new peaks attributed to $\mathrm{W}$ elements (from HPW molecular) begin to appear in Figure 2(b). A decline of the $\mathrm{C}$ signal intensity is observed in comparison with pure yeast cores. Also, these changes have been further ascertained by quantitative evaluation of the surface atom concentration of the primitive yeast and the HPW@yeast composites. From the inset table in Figure 2, we can see that the $\mathrm{W}$ element on the surface of HPW@yeast microspheres is $11.36 \%$. Compared with bare yeast core, a decrease in the atomic concentration of the $\mathrm{C}$ and $\mathrm{S}$ elements and an increase in the $\mathrm{P}$ and $\mathrm{O}$ elements are detected due to the coverage of HPW onto surface of the yeast. The previously mentioned results provide assertive evidence that our synthesis method is effective in embedding HPW uniformly onto the yeast surface without disordering the structure of yeast cells.

3.2. XRD. XRD patterns of yeast, HPW and HPW@yeast composite, are recorded in Figure 3. The typical XRD pattern of yeast is recorded in Figure 3(a). The broad peak around $2 \theta=20^{\circ}$ indicates that the yeast supports can be assigned to amorphous species. In Figure 3(c) the positions of the sharp peaks below $2 \theta=10^{\circ}$ could be ascribed to cubic phase $\mathrm{H}_{3} \mathrm{PW}_{12} \mathrm{O}_{40} \cdot 6 \mathrm{H}_{2} \mathrm{O}$ (Hydrogen Tungsten Phosphate Hydrate) and were indexed to the reported data (JCPDS 


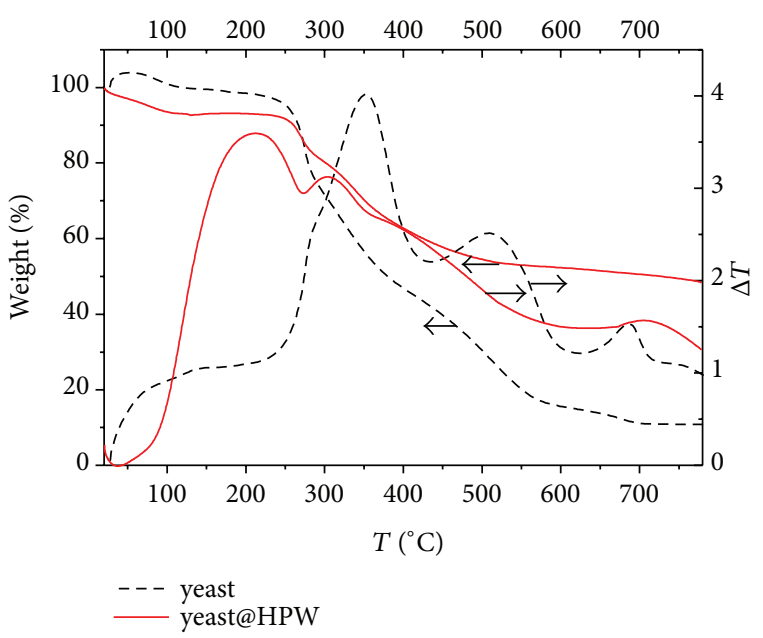

FIGURE 4: TG and DTA curves of yeast and HPW@yeast samples.

50-0304). The other remaining diffraction peaks match well with the standard diffraction data (JCPDS 50-0657) of the cubic structure $\mathrm{H}_{3} \mathrm{PW}_{12} \mathrm{O}_{40}$ (12-tungstophosphoric acid). The XRD analysis coincides with the Keggin structure of HPW. In Figure 3(b), the HPW@yeast samples show that an obvious diffraction peak around $2 \theta=20^{\circ}$ arose from the amorphous structure of yeast, and some inconspicuous peaks of HPW crystal suggest that the attached HPW molecule has monolayer dispersion on the surface of yeast core.

3.3. TG-DTA. TG/DTA curves of yeast and HPW@yeast samples are recorded in Figure 4. It is noted that the weight loss of as-obtained HPW@yeast particles can be divided into three stages in the TG curve. The weight loss of ca $6 \%$ was observed below $100^{\circ} \mathrm{C}$ because of the release of less stable physically absorbed water in HPW and the evaporation of adsorbed moisture remaining in the yeast cells, which is accompanied by a broad endothermic peak. The rapid weight loss of about $40 \%$ at the temperature range of $250-500^{\circ} \mathrm{C}$ may contribute to the desorption of crystal water in HPW and the thermal decomposition of yeast biomass, which is accompanied by two exothermic peaks below $500^{\circ} \mathrm{C}$. A little reduction in weight was observed above $500^{\circ} \mathrm{C}$, which could be associated with the loss of frame water in HPW and the destruction of its structure. This result was supported by the DTA curve which shows an exothermic peak at about $704^{\circ} \mathrm{C}$. Furthermore, compared with the related literature of the temperature of complete decomposition [22], the attachments of HPW onto the surface of yeast have evidently enhanced the thermal stability of the HPW molecule.

3.4. FT-IR. In order to confirm the chemical structure of the HPW@yeast composites, FT-IR spectra of yeast cells, pure HPW, and HPW@yeast composites and their intermediate in the synthesis stages are recorded, respectively. The results are shown in Figure 5. The characteristic adsorption peaks of bare yeast in Figure 5(a) at 3423.61, 2927.91, 1641.40, and $1076.26 \mathrm{~cm}^{-1}$ are ascribed to the $\mathrm{O}-\mathrm{H}$ stretching vibration,

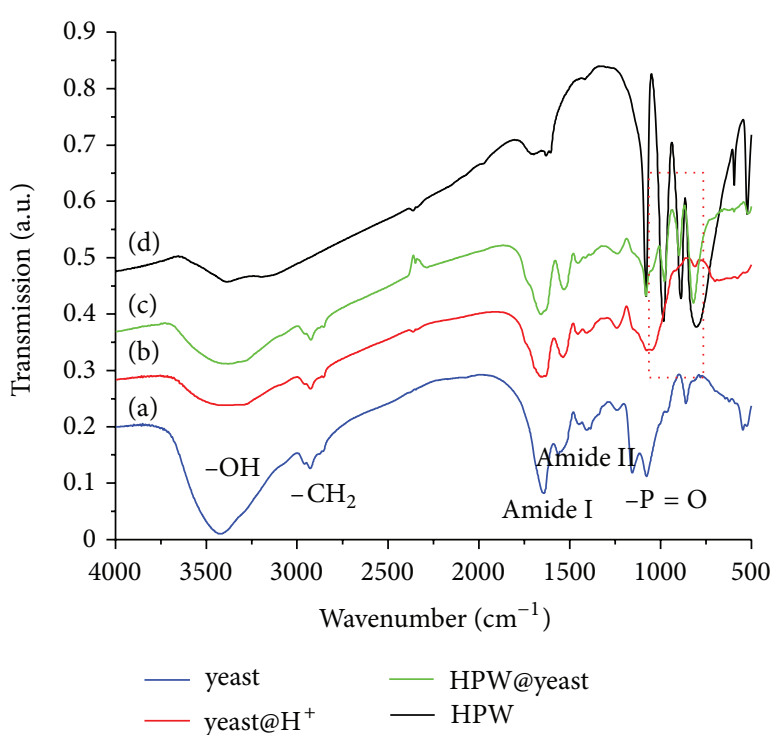

(a)

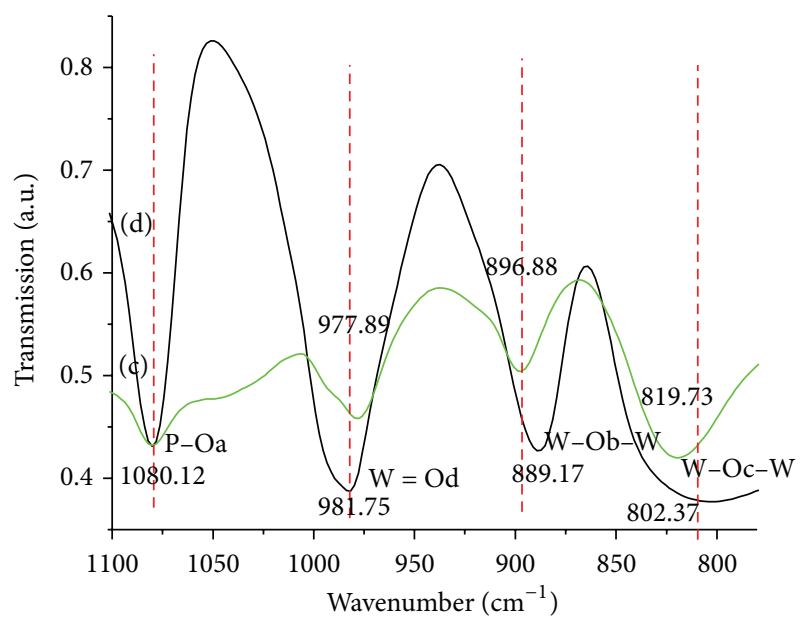

(b)

FIGURE 5: FT-IR spectra of (a) pristine yeast, (b) yeast treated by $\mathrm{H}_{2} \mathrm{SO}_{4}$ solution, (c) HPW@yeast microspheres, and (d) HPW.

$\mathrm{CH}_{2}$ asymmetric stretching vibration, amide group, and $\mathrm{C}-$ O stretching vibration, separately [23-27]. In the case of pure HPW in Figure 5(d), the presences of the finger print bands below $1100 \mathrm{~cm}^{-1}$ are characteristic of the $\mathrm{PW}_{12} \mathrm{O}_{4}{ }^{3-}$ ion with the Keggin structures. The $\mathrm{PW}_{12} \mathrm{O}_{4}{ }^{3-}$ Keggin anion structure consists of a $\mathrm{PO}_{4}$ tetrahedron surrounded by four $\mathrm{W}_{3} \mathrm{O}_{9}$ groups formed by edge-sharing octahedral. These groups are connected to each other by corner-sharing oxygen [28, 29]. This structure generates different types of oxygen atoms, which are responsible for the signature of FT-IR bands for the Keggin anions below $1100 \mathrm{~cm}^{-1}[30,31]$. The main adsorption peak at $1080.12 \mathrm{~cm}^{-1}$ is ascribed to $\mathrm{P}-\mathrm{Oa}$ stretching and the peak at $981.75 \mathrm{~cm}^{-1}$ derives from $\mathrm{W}=\mathrm{Od}$ stretching. The other peaks at $889.17 \mathrm{~cm}^{-1}$ and $802.37 \mathrm{~cm}^{-1}$ are due to the $\mathrm{W}-\mathrm{Ob}-\mathrm{W}$ and $\mathrm{W}-\mathrm{Oc}-\mathrm{W}$ bridges, respectively [32-34]. 

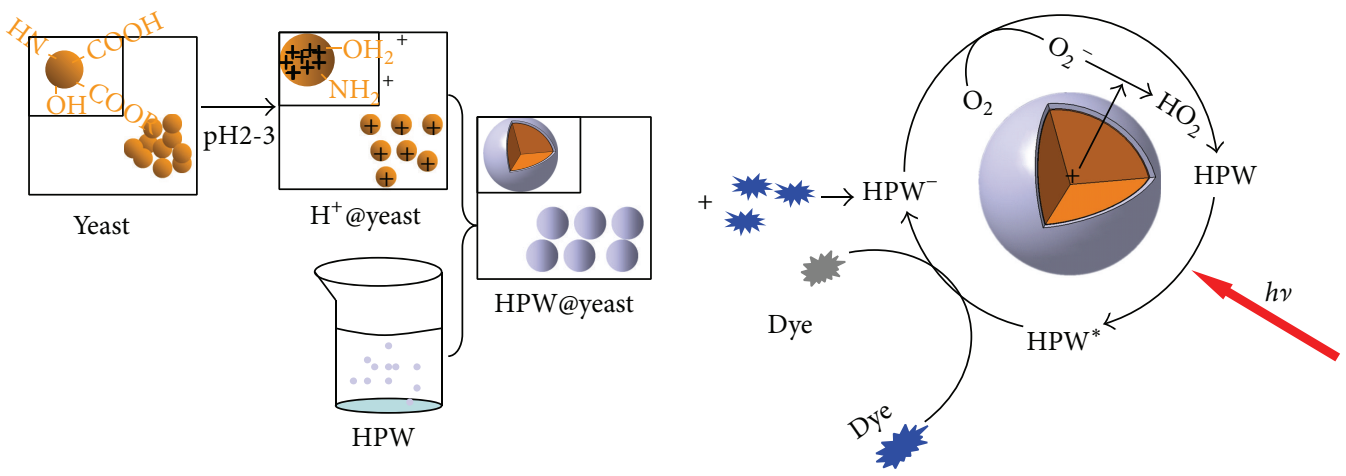

Scheme 1: The formation mechanism of the HPW@yeast composite particles and their synergetic effect on the decoloration of azo dye aqueous solution.

From Figure 5(c), the simultaneous existence of typical infrared bands of Keggin unit and yeast cells implies that the HPW has been loaded onto the surface of yeast cells and the Keggin structure has been preserved. Moreover, it can be found that the $\mathrm{W}=\mathrm{Od}$ mode shifts from $981.75 \mathrm{~cm}^{-1}$ to $977.89 \mathrm{~cm}^{-1}$, the $\mathrm{W}-\mathrm{Ob}-\mathrm{W}$ mode moves from $889.17 \mathrm{~cm}^{-1}$ to $896.18 \mathrm{~cm}^{-1}$, and the absorption band of W-Oc-W shifts from $802.37 \mathrm{~cm}^{-1}$ to $819.73 \mathrm{~cm}^{-1}$. All the characteristic bands of $\mathrm{O}-\mathrm{H}, \mathrm{CH}_{2}$, amide group, and C-O in HPW@yeast shift at different degrees in comparison with pure yeast. These concurrent shifts can be attributed to the interaction between the Keggin anions in HPW and the functional groups on the surface of yeast cells, such as carboxyls, hydroxyls, and amide. The possible mechanism for the formation of HPW@yeast is illustrated in Scheme 1.

3.5. UV-Vis. UV-visible diffuse reflectance spectra (DRS) of yeast, HPW, and HPW@yeast are showed in Figure 6. In Figure 6(a), the HPW shows an adsorption peak at $267 \mathrm{~nm}$, which is attributed to the charge transfer transition of W$\mathrm{O}-\mathrm{W}$ bridge bond in Keggin anions [35]. From Figure 6(b), the absorption wavelength of HPW@yeast at around $300 \mathrm{~nm}$ can be assigned to HPW molecules embedded on the surface of yeast. Because of the interaction between HPW and yeast, the UV absorption of two peaks is shifted from $267 \mathrm{~nm}$ and $300 \mathrm{~nm}$ to $268 \mathrm{~nm}$ and $305 \mathrm{~nm}$, respectively. Additionally, the band edge of the HPW@yeast UV-Vis DRS is also red shifted $(460 \mathrm{~nm})$. The red shift mentioned-above made HPW@yeast possible for photochemical catalysis through a visible light excitation. A similar observation was made by Yuan et al. [36]. These results indicate that the primary Keggin structure has been introduced on the surface of yeast. This is also in agreement with the FT-IR analysis. Moreover, the photographs of HPW@yeast microspheres and pure yeasts are taken, respectively, in the insert images of Figure 6. We can see the color of the obtained HPW@yeast species exhibiting a slighter grey than the pure yeast, which was in accordance with its absorption spectrum.

3.6. The Settling Tests. In principle, using yeast as support in HPW@yeast products can encourage the composite microspheres exhibiting unique suspension ability. The

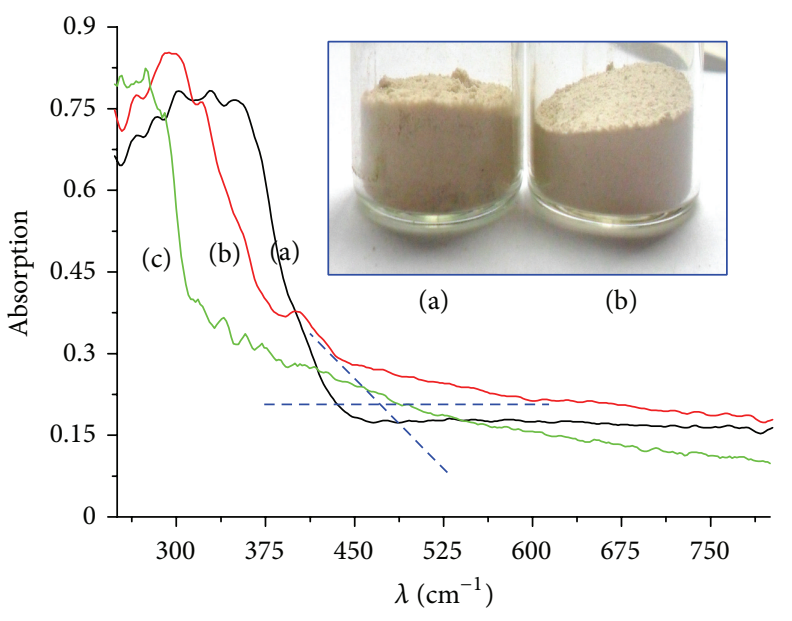

FIGURE 6: UV-Vis DRS spectra of (a) HPW, (b) HPW@yeast, and (c) pure yeast samples.

sedimentation performance of HPW@yeast microspheres in aqueous solutions is showed in Figure 7. In each experiment all the particles were dispersed in water without any additional additive. It is clearly observed that the HPW@yeast species have excellent suspension ability as that of the yeast. To be more specific, the setting ratios of pure yeast and the HPW@yeast samples only went down about 10.0\% and $20.0 \%$ separately after $280 \mathrm{~min}$. The scattered capacity of HPW@yeast is a bit worse than that of yeast due to the attachment of HPW onto the surface of yeast. The realistic sedimentation photographs at different time are recorded as the insert images in Figure 7. The outstanding suspension stability of HPW@yeast samples is ascribed to the apparent density of composite. As a kind of aquatic microorganisms, the wet density of yeast $\left(1.09 \pm 0.008 \mathrm{~g} \cdot \mathrm{cm}^{-3}\right)$ is almost equal to that of water. According to Stokes equation (2), lower apparent density of HPW@yeast particles will cause low sedimentation velocity [37]:

$$
V_{0}=\frac{2 \cdot(\rho-\sigma) \cdot g \cdot r^{2}}{9 \cdot \eta}
$$




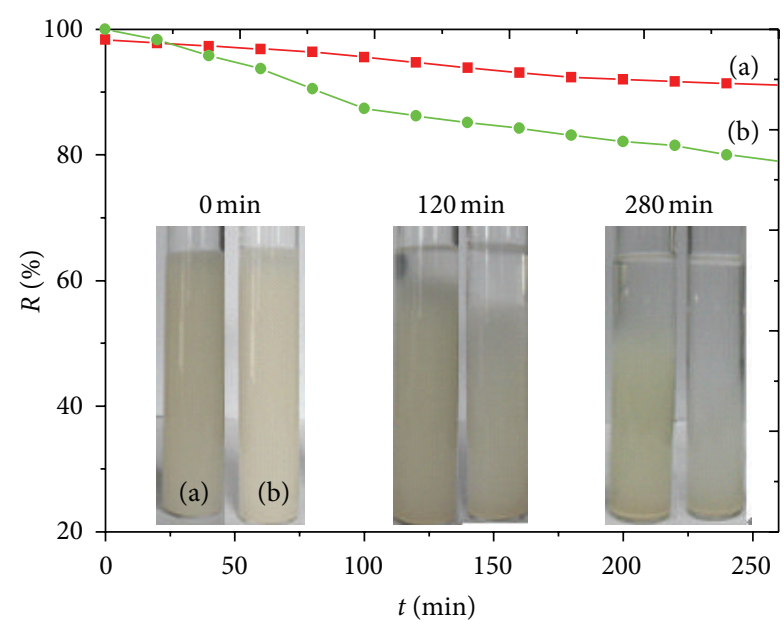

FIGURE 7: The settling curves of (a) pure yeast and (b) HPW@yeast microspheres.

In (2), $V_{0}$ is sedimentation velocity of the particles in carrier fluid; $r$ and $\rho$ are the radius and apparent density of the particles, respectively; $\sigma$ and $\eta$ are the density and viscosity of the carrier fluid, respectively; and $g$ is the gravitational constant. In the slurry reactor, it is well known that the good suspension ability of HPW@yeast microspheres could ensure that the catalysts maintain dispersed state for a long time in aqueous solution. That is not only beneficial to the adsorption of dye molecules but also made it possible for HPW to get the utmost out of light source to realize oxidizing organic pollutants by photocatalytic degradation. In addition, owing to the micrometer size of the yeast support, the HPW@yeast composite microspheres could recover and recycle from the reaction system rapidly, accomplished by common filtration.

3.7. Catalytic Performance. In order to examine the application taints of HPW@yeast microspheres for the removal of water contaminants, the aqueous solutions of cationic dyes Methylene Blue were taken as an example. The decolorization by $\mathrm{H}^{+} @ y e a s t$ (the yeast was treated with $\mathrm{H}_{2} \mathrm{SO}_{4}$ ) and HPW@yeast microsphere was carried out, respectively. From Figure 8(a) it is shown that the MB aqueous solution is barely photolyzed by UV irradiation only. From Figure 8(c), it can be seen that only $8.9 \%$ decolorization of MB dye can be achieved by combination of yeast and UV irradiation during the $150 \mathrm{~min}$ reaction time. The causes of decolorization of $\mathrm{MB}$ dye aqueous solution can be attributed to the absorption capacity of yeast. For the HPW@yeast composite catalyst, $98.1 \%$ of the MB was decomposed after 150 min of irradiation and the gradual fading of aqueous $\mathrm{MB}$ solution was observed. It is obvious that the decolorization function of HPW@yeast was effective. By contrast, it can also be concluded that the Keggin structure of HPW plays a key role in the decolorization of the MB. The reaction mechanism for the decolorization of aqueous MB by the yeast@HPW is proposed as follows $[38,39]$ :

$$
\begin{gathered}
\text { HPW@yeast } \stackrel{h v}{\longrightarrow} \mathrm{HPW}^{*} @ \text { yeast } \\
\mathrm{HPW}^{*} @ \text { yeast }+\mathrm{H}_{2} \mathrm{O} \longrightarrow \mathrm{HPW}^{-} @ \text { yeast }+\cdot \mathrm{OH}
\end{gathered}
$$

$$
\begin{gathered}
\mathrm{HPW}^{-} @ \text { yeast }+\mathrm{O}_{2} \longrightarrow \mathrm{HPW} @ \text { yeast }+\mathrm{O}_{2}^{-} \\
\mathrm{O}_{2}^{-}+\mathrm{H}^{+} \longrightarrow \mathrm{HO}_{2}
\end{gathered}
$$

When a photon of UV light shines on the HPW surface, the $\mathrm{O}(2 \mathrm{p})->\mathrm{W}(5 \mathrm{~d})$ charge transfer in the Keggin structure leads to the formation of excited-state species (HPW) ${ }^{*}(3)$. The excited-state species (HPW) ${ }^{*}$ have higher oxidation capacity through forming electron-hole pairs. In liquid-phase reaction, the photoholes react with the water molecules, and $\cdot \mathrm{OH}$ radicals are generated (4). $\bullet \mathrm{OH}$ radicals are strong and unselective oxidant species in favor of totally oxidative degradation and mineralization for organic substrates. The active $\cdot \mathrm{OH}$ radicals lead to the degradation of the $\mathrm{MB}$. Alternatively, in the presence of dioxygen, the reduced catalyst $\left(\mathrm{HPW}^{-}\right)$undergoes an easy reoxidation through the transfer of electron from reduced species to dioxygen (5). Thus the activated oxygen species $\mathrm{HO}_{2}$ radical formed (6). However, it is documented that surface-bound and solvated - $\mathrm{OH}$ radicals are a main oxidant to attack dye $[38,39]$. During the regeneration of catalysis, the positive charged surface of yeast could be an efficient electron acceptor to make HPW keep the photocatalytic cycle persisting. As we all know, there are diverse functional groups which are contained in chemical substances in the yeast cell wall, such as carboxyl, amine, hydroxyl, and phosphoryl. These functional groups could make yeast have different zeta potential, the surface charges of the particles in the same solvent at diverse acidbase intense. The isoelectric point of yeast is around $\mathrm{pH} 3.3$ $[40,41]$. When the $\mathrm{pH}$ of the solution is under 3.3 , the zeta potential of yeast is above zero, displaying surface positive charge (Scheme 1). The surface positive charge catalyzes the oxidation of $\mathrm{O}_{2}{ }^{-}$into the activated oxygen species $\mathrm{HO}_{2}$, which accelerates the catalytic reaction rates of HPW@yeast as the result. In order to prove our conjecture of the yeast's role in catalysis, the decolorization of anionic dye Cong Red was also tested. It could be seen from Figure 6 that the degradation rate for Cong red decreases much than that of $\mathrm{MB}$ at the same initial mole concentration. One reason for decrease of the reaction rate would be assigned to the decrease of the concentration of the positive charge of yeast because Cong Red as an anionic dye neutralizes the positive charge on the surface of yeast. It is just another proof of our thought that the positive charge in the surface of yeast can speed up the discoloration rate of dye. The further details mechanism is currently under investigation.

One of the advantages of using heterogeneous catalysts is the possibility of their reusability [42]. The lifetime of the HPW@yeast composite catalyst has been studied by running the reaction successively with the same catalyst which was separated by simple centrifugation without other treatment. From Figure 9, it can be seen that the catalytic activity of HPW@yeast had no significant decrease after four runs. It once again demonstrated that the HPW@yeast composites could simply recycle and recover from the reaction system. The excellent reusability of the HPW@yeast catalyst indicates that product has better stability and negligible loss of the Keggin units. 


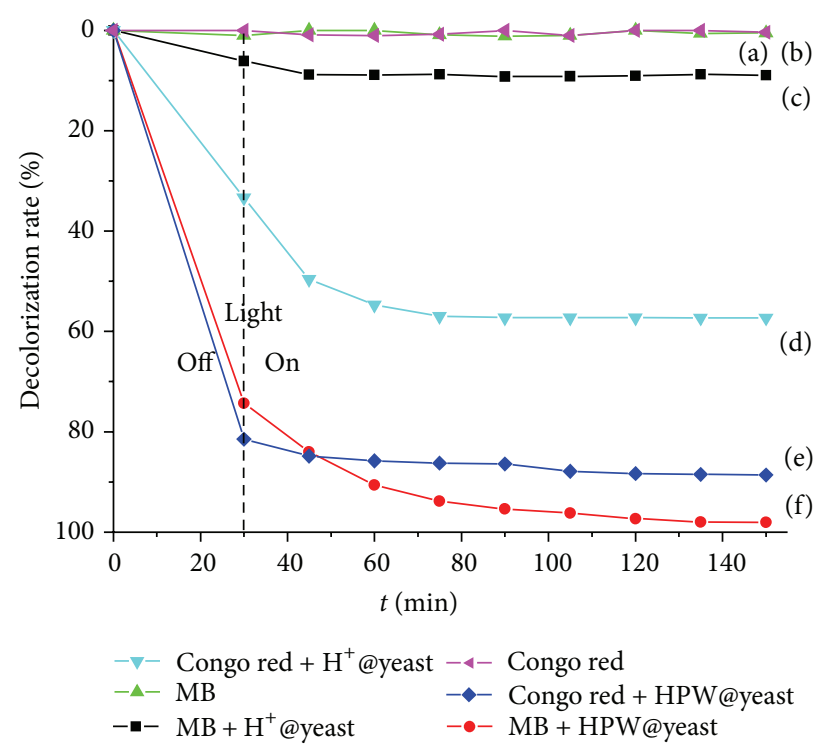

FIGURE 8: Discolorations reaction of $\mathrm{MB}$ and Congo red.

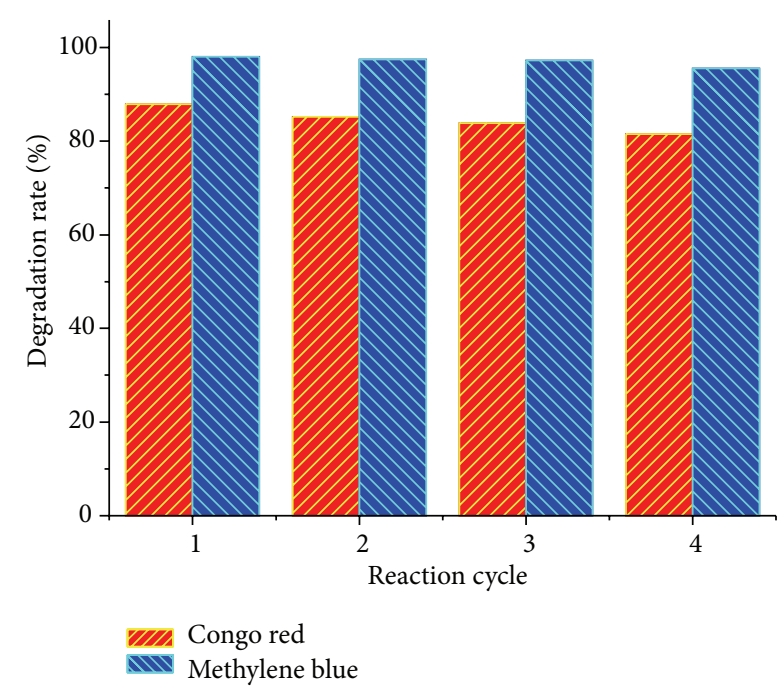

FIGURE 9: The recycle use of HPW@yeast in decoloring of MB and Cong red.

\section{Conclusion}

In summary, we have successfully prepared the HPW@yeast composite microspheres through impregnation-adsorption technique by tuning $\mathrm{pH}$ of the aqueous yeast suspensions. Physical-chemical characterization results suggest that HPW is monodisperse on the surface of yeast and the main structure belongs to Keggin unit. The composites have uniform size and good thermal stability. The obtained samples have outstanding suspension property and are easy to be separated under the conventional centrifugation. The catalytic performance indicates that the HPW@yeast microspheres have potential applications for the removal of a range of anionic and cationic dyes from wastewater. More importantly, the composite catalysts can be used repeatedly without significant decrease of activity. It seems that the yeast support plays an important role in regeneration of catalyst. The present method can be extended to the synthesis of other hybrid microsphere of different sizes and shapes by preselecting suitable biosupport.

\section{Acknowledgments}

This work was financially supported by China Postdoctoral Science Special Foundation, National Natural Science Foundation of China (Grant no. 21176031), and Natural Science Foundation of Shaanxi Province (no. 2011JM2011).

\section{References}

[1] N. Mizuno and M. Misono, "Heterogeneous catalysis," Chemical Reviews, vol. 98, no. 1, pp. 199-217, 1998.

[2] Y. H. Guo, C. W. Hu, X. L. Wang et al., "Microporous decatungstates: synthesis and photochemical behavior," Chemistry of Materials, vol. 13, no. 11, pp. 4058-4064, 2001.

[3] L. Li, Q. Y. Wu, Y. H. Guo, and C. W. Hu, "Effect of thermal treatment on surface and bulk properties of Fe/ZSM-5 zeolites prepared by different methods," Microporous and Mesoporous Materials, vol. 87, no. 2, pp. 93-102, 2005.

[4] M. M. Heravi, F. Derikvand, and F. F. Bamoharram, "Highly efficient, four-component one-pot synthesis of tetrasubstituted imidazoles using Keggin-type heteropolyacids as green and reusable catalysts," Journal of Molecular Catalysis A, vol. 263, no. 1-2, pp. 112-114, 2007.

[5] A. Heydaria, S. Khaksara, M. Sheykhana, and M. Tajbakhsh, " $\mathrm{H}_{3} \mathrm{PMo}_{12} \mathrm{O}_{40}$ as a new and reusable catalyst for Mukaiyama and Mannich reactions in heterogeneous media," Journal of Molecular Catalysis A, vol. 287, no. 1-2, pp. 5-8, 2008.

[6] A. Kumar, P. Singh, S. Kumar, R. Chandra, and S. Mozumdar, "A facile one-pot synthesis of thioethers using heteropoly acids," Journal of Molecular Catalysis A, vol. 276, no. 1-2, pp. 95-101, 2007.

[7] X. M. Yan, J. H. Lei, D. Liu, Y. C. Wu, and W. Liu, "Synthesis and catalytic properties of mesoporous phosphotungstic acid $/ \mathrm{SiO}_{2}$ in a self-generated acidic environment by evaporation-induced self-assembly," Materials Research Bulletin, vol. 42, no. 11, pp. 1905-1913, 2007.

[8] S. T. Li, C. D. Wu, Y. S. Yan, X. M. Lü, and P. W. Huo, "Photodegradation of organic contaminant by heteropoly acid," Progress in Chemistry, vol. 20, no. 5, pp. 690-697, 2008.

[9] P. Kormali, D. Dimoticali, D. Tsipi, A. Hiskia, and E. Papaconstantinou, "Photolytic and photocatalytic decomposition of fenitrothion by $\mathrm{PW}_{12} \mathrm{O}_{40}^{3-}$ and $\mathrm{TiO}_{2}$ : a comparative study," Applied Catalysis B, vol. 48, no. 3, pp. 175-183, 2004.

[10] H. Hori, E. Hayakawa, K. Koike, H. Einaga, and T. Ibusuki, "Decomposition of nonafluoropentanoic acid by heteropolyacid photocatalyst $\mathrm{H}_{3} \mathrm{PW}_{12} \mathrm{O}_{40}$ in aqueous solution," Journal of Molecular Catalysis A, vol. 211, no. 1-2, pp. 35-41, 2004.

[11] X. Yang, G. Yu, L. R. Kong, and L. S. Wang, "Kinetic Study on Photodegradation of Acid Red 3B Catalyzed by Heteropoly Acid," Environmental Science, vol. 23, no. 3, pp. 40-43, 2002.

[12] K. Su, Z. Li, B. Cheng, L. Zhang, M. Zhang, and J. Ming, "The studies on the Friedel-Crafts acylation of toluene with acetic anhydride over $\mathrm{HPW} / \mathrm{TiO}_{2}$," Fuel Processing Technology, vol. 92, no. 10, pp. 2011-2015, 2011. 
[13] Y. J. Zeng, H. J. Yu, and L. Shi, "Structure and Catalytic Activity of Phosphotungstic Acid Supported on Y-Zeolite," Chemical Reaction Engineering and Technology, vol. 23, no. 6, pp. 542-547, 2007.

[14] F. Gao, J. W. Sun, and S. H. Zhong, "Synthesis and characterization of heteropoly acid catalyst supported on carbonized resin," Chinese Journal of Catalysis, vol. 19, no. 2, pp. 187-190, 1999.

[15] L. Y. Wen, S. K. Shen, and E. Z. Min, "Physicochemical and Catalytic Properties of 12-Phosphotungstic Acid Supported on Different Silica," Chinese Journal of Catalysis, vol. 21, no. 6, pp. 524-528, 2000.

[16] Z. Obalı and T. Dogu, "Activated carbon-tungstophosphoric acid catalysts for the synthesis of tert-amyl ethyl ether (TAEE)," Chemical Engineering Journal, vol. 138, no. 1-3, pp. 548-555, 2008.

[17] S. J. Yang, Y. J. Zhang, and H. L. Zhang, "Degradation of Methyl Orange Solution over $\mathrm{H}_{3} \mathrm{PW}_{12} \mathrm{O}_{40} / \mathrm{MCM}-48$," Chemical Reaction Engineering and Technology, vol. 27, no. 6, pp. 562-566, 2011.

[18] W. He, X. Tian, Y. Du et al., "Biologically formed hollow cuprous oxide microspheres," Materials Science and Engineering C, vol. 30, no. 5, pp. 758-762, 2010.

[19] D. Weinzierl, A. Lind, and W. Kunz, "Hollow $\mathrm{SiO}_{2}$ microspheres produced by coating yeast cells," Crystal Growth and Design, vol. 9, no. 5, pp. 2318-2323, 2009.

[20] B. Bai, N. Quici, Z. Y. Li, and G. L. Puma, "Novel one step fabrication of raspberry-like $\mathrm{TiO}_{2} @ y e a s t$ hybrid microspheres via electrostatic-interaction-driven self-assembled heterocoagulation for environmental applications," Chemical Engineering Journal, vol. 170, no. 2-3, pp. 451-456, 2001.

[21] B. Bai, W. S. Guan, Z. Y. Li, and G. L. Puma, "Bio-template route for facile fabrication of $\mathrm{Cd}(\mathrm{OH})_{2} @ y e a s t$ hybrid microspheres and their subsequent conversion to mesoporous $\mathrm{CdO}$ hollow microspheres," Materials Research Bulletin, vol. 46, no. 1, pp. 2631, 2011.

[22] B. S. Li, Z. X. Liu, C. Y. Han, W. Ma, and S. J. Zhao, "In situ synthesis, characterization, and catalytic performance of tungstophosphoric acid encapsulated into the framework of mesoporous silica pillared clay," Journal of Colloid and Interface Science, vol. 377, no. 1, pp. 334-341, 2012.

[23] S. J. Joris and C. H. Amberg, "Nature of deficiency in nonstoichiometric hydroxyapatites. II. Spectroscopic studies of calcium and strontium hydroxyapatites," The Journal of Physical Chemistry, vol. 75, no. 20, pp. 3172-3178, 1971.

[24] M. Beekes, P. Lasch, and D. Naumann, "Analytical applications of Fourier transform-infrared (FT-IR) spectroscopy in microbiology and prion research," Veterinary Microbiology, vol. 123, no. 4, pp. 305-319, 2007.

[25] K. C. Blakeslee and R. A. Condrate, "Vibrational spectra of hydrothermally prepared hydroxyapatites," Journal of the American Ceramic Society, vol. 54, no. 11, pp. 559-563, 1971.

[26] K. J. Rothschild and N. A. Clark, "Anomalous amide I infrared absorption of purple membrane," Science, vol. 204, no. 4390, pp. 311-312, 1979.

[27] R. A. Nyquist and R. O. Kagel, Infrared Spectra of Inorganic Compounds, Academic Press, New York, NY, USA, 1971.

[28] J. Yang, M. J. Janik, D. Ma et al., "Location, acid strength, and mobility of the acidic protons in Keggin $12-\mathrm{H}_{3} \mathrm{PW}_{12} \mathrm{O}_{40}$ : a combined solid-state NMR spectroscopy and DFT quantum chemical calculation study," Journal of the American Chemical Society, vol. 127, no. 51, pp. 18274-18280, 2005.
[29] A. E. R. S. Khdera, H. M. A. Hassana, and M. S. El-Shall, "Acid catalyzed organic transformations by heteropoly tungstophosphoric acid supported on MCM-41," Applied Catalysis A, vol. 411-412, pp. 77-86, 2012.

[30] Y. S. Kim, F. Wang, M. Hickner, T. A. Zawodzinski, and J. E. McGrath, "Fabrication and characterization of heteropolyacid $\left(\mathrm{H}_{3} \mathrm{PW}_{12} \mathrm{O}_{40}\right)$ /directly polymerized sulfonated poly(arylene ether sulfone) copolymer composite membranes for higher temperature fuel cell applications," Journal of Membrane Science, vol. 212, no. 1-2, pp. 263-282, 2003.

[31] L. Zhang, H. Q. He, R. Kamal S/O Abdul Rasheed et al., "Fabrication of novel phosphotungstic acid functionalized mesoporous silica composite membrane by alternative gelcasting technique," Journal of Power Sources, vol. 221, pp. 318327,2013

[32] L. Zhang, Q. Jin, L. Shan, Y. Liu, X. Wang, and J. Huang, " $\mathrm{H}_{3} \mathrm{PW}_{12} \mathrm{O}_{40}$ immobilized on silylated palygorskite and catalytic activity in esterification reactions," Applied Clay Science, vol. 47, no. 3-4, pp. 229-234, 2010.

[33] P. Staiti, S. Freni, and S. Hocevar, "Synthesis and characterization of proton-conducting materials containing dodecatungstophosphoric and dodecatungstosilic acid supported on silica," Journal of Power Sources, vol. 79, no. 2, pp. 250-255, 1999.

[34] X. L. Sheng, Y. M. Zhou, Y. W. Zhang, M. W. Xue, and Y. Z. Duan, "Immobilization of 12-tungstophosphoric acid on LaSBA-15 and its catalytic activity for alkylation of o-xylene with styrene," Chemical Engineering Journal, vol. 179, pp. 295301, 2012.

[35] P. M. Rao, A. Wolfson, S. Kababya, S. Vega, and M. V. Landau, "Immobilization of molecular $\mathrm{H}_{3} \mathrm{PW}_{12} \mathrm{O}_{40}$ heteropolyacid catalyst in alumina-grafted silica-gel and mesostructured SBA-15 silica matrices," Journal of Catalysis, vol. 232, no. 1, pp. 210-225, 2005.

[36] J. Yuan, P. Yue, and L. Wang, "A study on the magnetically supported heteropolyacid nanophase catalysts," Powder Technology, vol. 202, no. 1-3, pp. 190-193, 2010.

[37] H. T. Pu, F. J. Jiang, and Z. L. Yang, "Preparation and properties of soft magnetic particles based on $\mathrm{Fe}_{3} \mathrm{O}_{4}$ and hollow polystyrene microsphere composite," Materials Chemistry and Physics, vol. 100, no. 1, pp. 10-14, 2006.

[38] Y. H. Guo, Y. H. Wang, C. W. Hu et al., "Microporous polyoxometalates poms $/ \mathrm{SiO}_{2}$ : synthesis and photocatalytic degradation of aqueous organocholorine pesticides," Chemistry of Materials, vol. 12, no. 11, pp. 3501-3508, 2000.

[39] Y. Bin, Y. Zhou, Y. X. Jing et al., "Photocatalytic degradation of aqueous 4-chlorophenol by silica-immobilized polyoxometalates," Environmental Science \& Technology, vol. 36, no. 6, pp. 1325-1329, 2002.

[40] M. Mercier-Bonin, K. Ouazzani, P. Schmitz, and S. Lorthois, "Study of bioadhesion on a flat plate with a yeast/glass model system," Journal of Colloid and Interface Science, vol. 271, no. 2, pp. 342-350, 2004.

[41] A. Bingol, H. Ucun, Y. K. Bayhan, A. Karagunduz, A. Cakici, and B. Keskinler, "Removal of chromate anions from aqueous stream by a cationic surfactant-modified yeast," Bioresource Technology, vol. 94, no. 3, pp. 245-249, 2004.

[42] E. Rafiee and S. Shahebrahimi, "Nano silica with high surface area from rice husk as a support for 12-tungstophosphoric acid: an efficient nano catalyst in some organic reactions," Chinese Journal of Catalysis, vol. 33, no. 8, pp. 1326-1333, 2012. 

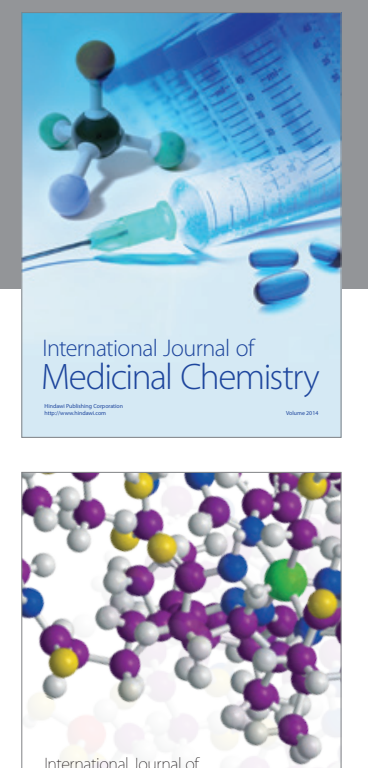

\section{Carbohydrate} Chemistry

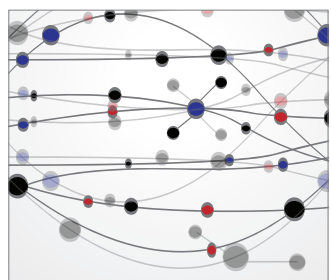

The Scientific World Journal
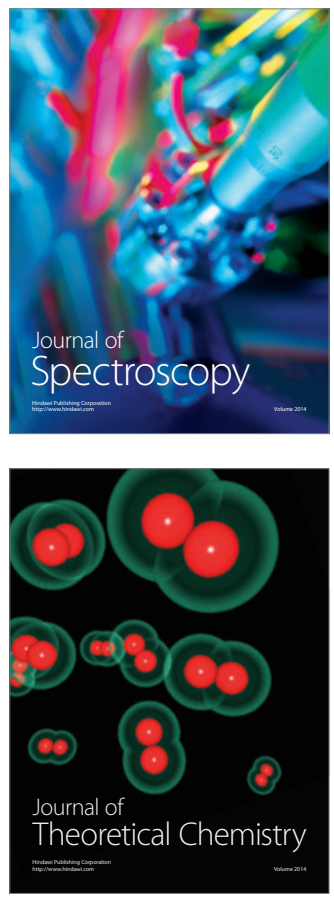
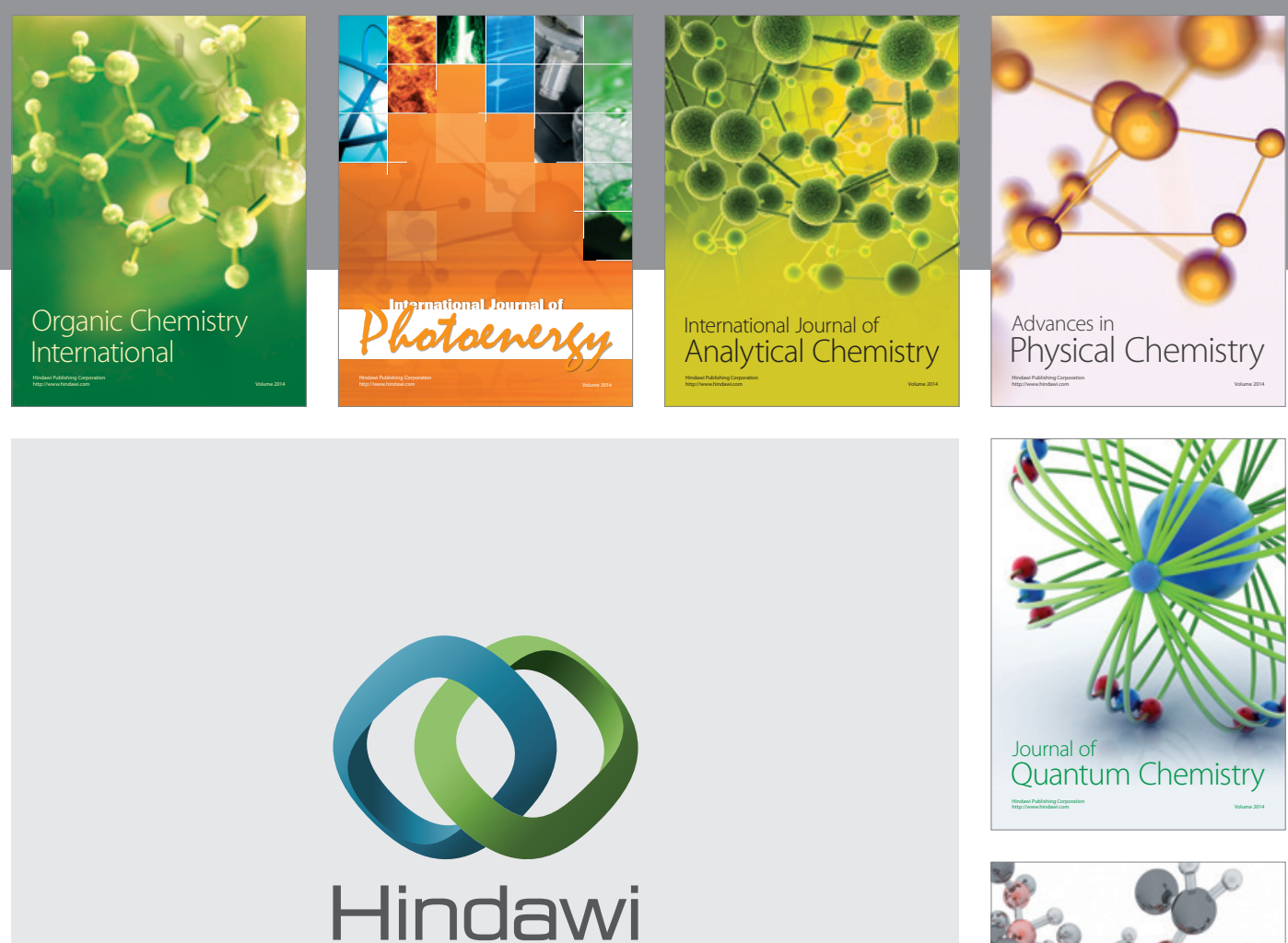

Submit your manuscripts at

http://www.hindawi.com

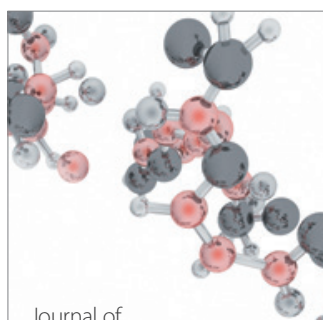

Analytical Methods

in Chemistry

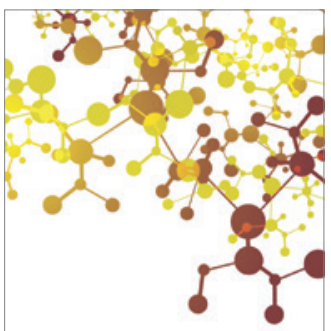

Journal of

Applied Chemistry

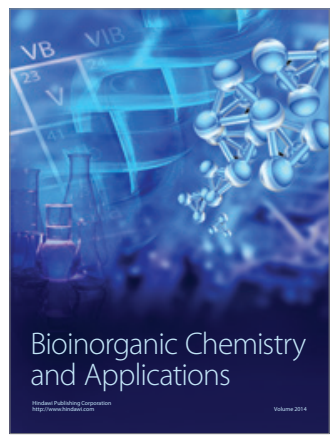

Inorganic Chemistry
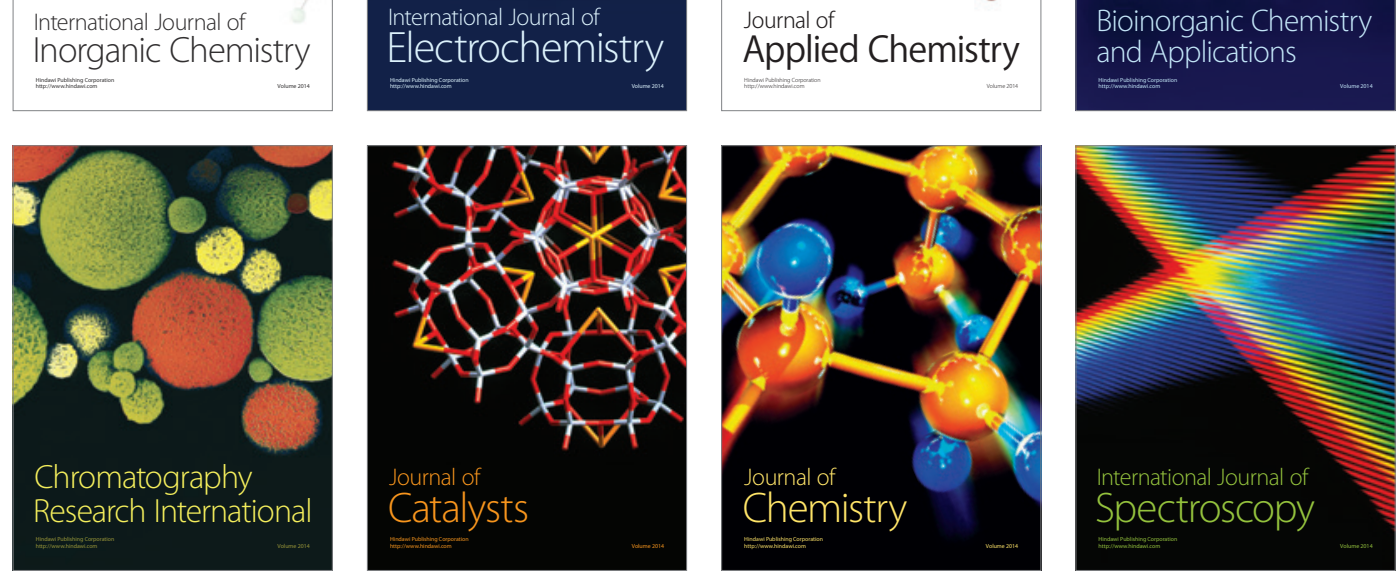